\title{
Comparative Study of Neem (Azadirachta indica), Bitter Gourd (Momordica charantia) extract as Herbal Anthelmintic and Albendazole as Chemical Anthelmintic in Controlling Gastrointestinal Nematodes in Goats
}

\author{
F. X. Priscilla ${ }^{1}$, M. R. Amin* ${ }^{1}$ and S. Rahman ${ }^{2}$ \\ ${ }^{I}$ Faculty of Agro Based Industry, ${ }^{2}$ Faculty of Earth Science, University Malaysia Kelantan, Locked Bag No 100. \\ 17600 Jeli, Kelantan, Malaysia
}

\begin{abstract}
The comparative efficiency of methanol extracts of Neem (Azadirachta indica), Bitter Gourd (Momordica charantia) and chemical anthelmintic Albendazole on gastrointestinal nematodes infected goats were evaluated by egg per gram (EPG) count for a period of approximately three weeks. Twelve Kambing Katjang goats naturally infested with gastrointestinal parasite were selected based on EPG count (>300 EPG) and divided into four groups each consisting of three goats. Treatment I was methanol extract of A.indica $(0.5$ $\mathrm{ml} / \mathrm{kg}$ body weight), treatment II was methanol extract of M.charantia $(1 \mathrm{ml} / \mathrm{kg}$ body weight), treatment III was chemical anthelmintic, Albendazole $(0.1 \mathrm{ml} / \mathrm{kg}$ body weight) and finally treatment IV was control. The treatments were administered on day 0 orally with single dosage and faecal egg count $(E P G)$ was determined on day 4, 8 and 20. Both methanol extract of A.indica and M.charantia showed significant $(p<0.01)$ reduction in controlling gastrointestinal nematodes infected goats compared to control group. A.indica showed gastrointestinal nematodes to be at a safe level (below 300 EPG) in goats on day 20 whereas M.charantia showed efficacy on day 8. Chemical anthelmintic showed no significant $(p>0.01)$ reduction throughout the three weeks. The use of herbal anthelmintics, A.indica and M.charantia has shown significant $(p<0.01)$ anthelmintic activity when compared with control group.
\end{abstract}

Keywords: Neem (Azadirachta indica), bitter gourd (Momordica charantia), Gastro-intestinal nematode, Albendazole, goat, EPG

\section{Introduction}

Endoparasitism or gastrointestinal nematodes has been identified as one of the important limiting factors in goat industry. It is estimated over $90 \%$ of the endoparasitism cases in small ruminants are due to Haemonchus contortus found in the abomasum of small ruminants (Sani et al., 1990). Gastrointestinal nematode infestation is manifested by reduced weight, lowered meat and milk production (Githigia et al., 2005). Sheep and goats production has an important social and economic function especially for small rural farmers, who rely on these animals for source of nutrition and income (Lateef, 2003). Several synthetic anthelmintic are available for the control of internal parasites. However over time these anthelmintic are becoming ineffective in terms of being resistant to parasites. On top of that, synthetic anthelmintics are quite expensive and are not easily available for small holders. A rising concern in livestock industry is its residue and toxicity level. More small holders are turning to herbal remedies for solution. Research has been done to study the anthelmintic properties of A.indica and M.charantia but very few have been done on its effectiveness differences. Malaysia is rich with many types of herbal plants but its true medicinal value is yet to be discovered. In many parts of the world, for centuries medicinal plants have been used to combat parasitism and are still used for this purpose. The use of medicinal plants for the prevention and treatment of gastrointestinal parasitism has its origin in ethnoveterinary medicine (Athansidou et al., 2007).The present study is undertaken with the following objectives: i) To study the effect of feeding A.indica and M.charantia as an anthelmintic in goat, ii) To compare the effectiveness between A.indica and M.charantia with chemical anthelmintic in goat

Study Area, Selection of Animals and Treatments

\section{Materials and Methods}

This experiment was conducted at a small scale subsistence-oriented family goat farm at Gemang, Jeli district, in Kelantan state. Twelve Kambing Katjang Goats were selected with a mixture of male and female. The animals were divided into four treatment groups each having 3 animals. Each group were then assigned to one of four treatments: i) methanol extracts of Neem (Azadirachta indica), ii) methanol extract of Bitter gourd (Momordica charantia), iii) chemical anthelmintic (Albendazole) and iv) control/ untreated animal 


\section{Collection and Processing of Herbal Anthelmintics Extract}

Fresh and healthy A.indica leaves and whole M.charantia were collected from local area. They were washed thoroughly to ensure it to be free from extraneous materials and then it was shadow dried. The materials were chopped and grinded for preparation of methanol plant extraction. Previously prepared plant materials were used for preparation of methanol plant extract. $50 \mathrm{~g}$ of both plant materials were macerated with $100 \mathrm{ml}$ methanol (100\%) for 48 hours. It was filtered using Whatman filter paper. The filtered materials were taken into a round bottom flask and then condensed by evaporation of solvent from filtrate in a water bath of $60^{\circ} \mathrm{C}$ to remove all the methanol solution from the extract up to final volume of $20 \mathrm{ml}$. After the evaporation of solvent from filtrate, the condensed extracts were preserved in tightly corked-labelled bottle and stored in a refrigerator until their screening for anthelmintic property. (Sujon et al., 2008)

\section{Herbal Anthelmintics Dose}

Dosage given for goats under Treatment I, A.indica extract was $0.5 \mathrm{ml} / \mathrm{kg}$ live weight whereas Treatment II, M.charantia extract was $1 \mathrm{ml} / \mathrm{kg}$ live weight of animal (Akbar et al., 2006; Al-Shaibani, 2009)

\section{Collection of Faeces}

Rectal faeces samples from each experimental animal were collected in the morning before they are fed with different treatments of herbal anthelmintics extract. After feeding each group of goats with its selected treatment, rectal faecal samples were collected on day 4, 8 and 20. About $5 \mathrm{~g}$ of faecal sample were obtained from each animal directly from rectum and were placed in separate plastic bag, packed and transferred to laboratory for microscopic examination. Nematode egg count was examined using McMaster counting technique method.

\section{Examination of faecal samples for parasite egg count}

$1 \mathrm{~g}$ of fresh faeces was accurately weighed and suspended in $9 \mathrm{ml}$ saturated sodium chloride $\mathrm{NaCl}$ (ratio 1:9). Therefore the dilution factor used was 10 . The suspension was strained through a fine sieve. The larger particles of faeces were removed and the residue was left to pass through. The suspension was stirred well in order to obtain a completely homogenous distribution of eggs in the liquid. Using a Pasteur pipette, one compartment of the McMaster slide was filled, tilting it a little to let air bubbles to escape. The same operation was repeated to fill the second counting chamber. After a few minutes eggs from the concentration solution floats up and sticks to the cover glass. Number of eggs was counted in both the compartment under low magnification.

Based on the following equation, the mean of two counts were recorded in calculating egg counts. Each compartment has a surface of $10 \times 10 \mathrm{sq} . \mathrm{mm}$. Spaces between object-glass and cover slip is $1.5 \mathrm{~mm}$.

Dimension of each compartment, $\frac{(10 \times 10 \times 1.5)}{1000}=0.15 \mathrm{cc}$

Each compartment contains $0.15 \mathrm{ml}$ liquid. $1 \mathrm{~g}$ of faeces is dissolved in $9 \mathrm{ml}$ of saturated $\mathrm{NaCl}$ solution, thus the dilution ratio, 1:9, dilution factor is 10 .

So, $E P G=\frac{\text { No of eggs in two chambers }}{\text { Area of two chambers }} \times$ Dilution factor

Suppose number of eggs counted in two chambers $=\mathrm{Y}$

$\mathrm{EPG}=\frac{\mathrm{Y}}{0.15+0.15} \times 10$

\section{Determination of Efficacy of different Treatment}

Efficacy of different treatment were determined by faecal egg count reduction test using the equation below (Al-Shaibani et al., 2009)

$$
\text { Efficacy }=\frac{E P G \text { pre treatment }- \text { EPG post treatment }}{\text { EPG pre treatment }} \times 100
$$

\section{Results and Discussion}

Methanol extract of A.indica exhibited significant $(\mathrm{p}<0.01)$ reduction in the EPG count in gastrointestinal nematodes infected goats on day 4 post-treatment compared to EPG count of day 0 (Table 1). On post-treatment day 8 there was significant $(\mathrm{p}<0.01)$ reduction on EPG counts until day 20 as well. The mean EPG count of day 0 , day 4, day 8 and day 20 are 970.36, 651.86, 355.57 and 114.80. These clearly show the treatment efficacy (Table 3) on day 4 was $32.80 \%$, on day 8 was $63.40 \%$ and on day 20 was $88.17 \%$. EPG count on day 20 was below 300 means that goats treated with methanol extract of A.indica could successfully maintained gastrointestinal nematode at safe level until 3 weeks post treatment. Table 2 clearly shows the comparative difference between A.indica treated group and control group. On day 0 , the difference between the two groups was non-significant $(\mathrm{p}>0.05)$. However on day 4 , day 8 and day 20 significant $(\mathrm{p}<0.01)$ differences were recorded. The percentage of differences between A.indica treated group and control on day 0 was merely 
$4.03 \%$, but on day 4 , day 8 and day 20 the treatment efficacy was $35.53 \%, 65.94 \%$ and $88.72 \%$ respectively. This result is in conformity with earlier reports made by Sujon et al. (2008), Chandrawathani et al. (2006), Worku et al. (2009) and Costa et al. (2008).

Methanol extract of M.charantia in Table 1 , shows there is significant $(\mathrm{p}<0.01)$ reduction in the EPG count in gastrointestinal nematodes infected goats on day 4 post treatment compared to EPG count of day 0. This reduction on EPG count was significantly $(\mathrm{p}<0.01)$ maintained until day 8 through day 20. The mean EPG count of day 0, day 4, day 8 and day 20 under bitter gourd treatment regime was 855.55, 559.24, 288.90 and 622.23 , respectively. These clearly show the treatment efficacy (Table 3) on day 4 was 34.63\%, day 8 was $66.23 \%$ and day 20 was $27.27 \%$. Comparative differences between M.charantia treated group and control group shows (Table 2) that on day 0 the differences were significant $(\mathrm{p}<0.05)$. On day 4, day 8 and also day 20 the differences recorded between these two groups were significant $(\mathrm{p}<0.01)$. The treatment efficacy between M.charantia treated group and control group on day 0, day 4, day 8 and day 20 was $15.39 \%, 44.69 \%, 72.33 \%$ and $38.91 \%$ respectively. This present results are again in good agreement with the findings of Sujon et al. (2008)

Table 1: EPG count comparative between pre-treatment and post-treatment of different groups of treatment

\begin{tabular}{|c|c|c|c|c|c|c|c|}
\hline & \multicolumn{4}{|c|}{ Mean EPG ( Mean \pm SE) } & \multicolumn{3}{|c|}{ t-value } \\
\hline \multirow[t]{2}{*}{ Treatment } & Pre- & \multicolumn{3}{|c|}{ Post-treatment } & D0-D4 & D0-D8 & D0-D20 \\
\hline & Day 0 & Day 4 & Day 8 & Day 20 & & & \\
\hline $\begin{array}{c}\text { Neem } \\
(0.5 \mathrm{ml} / \mathrm{kg} \text { body } \\
\text { weight }) \\
(\mathrm{n}=9) \\
\end{array}$ & $\begin{array}{l}970.36 \\
\pm 166.15\end{array}$ & $\begin{array}{l}651.86 \\
\pm 91.81\end{array}$ & $\begin{array}{l}355.57 \\
\pm 48.11\end{array}$ & $\begin{array}{l}114.80 \\
\pm 21.60\end{array}$ & $4.21 * *$ & $4.82 * *$ & $5.88^{* *} *$ \\
\hline $\begin{array}{c}\text { Bitter Gourd } \\
(1 \mathrm{ml} / \mathrm{kg} \text { body } \\
\text { weight) } \\
(\mathrm{n}=9)\end{array}$ & $\begin{array}{l}855.55 \\
\pm 70.71\end{array}$ & $\begin{array}{l}559.24 \\
\pm 84.58\end{array}$ & $\begin{array}{l}288.90 \\
\pm 44.80\end{array}$ & $\begin{array}{l}622.23 \\
\pm 61.61\end{array}$ & $18.36^{* * *}$ & $17.76^{* *}$ & $7.80^{*}$ \\
\hline $\begin{array}{c}\text { Chemical } \\
\text { anthelmintic } \\
\text { (Albendazole) } \\
\text { (0.1 ml/kg body } \\
\text { weight) } \\
(\mathbf{n}=9)\end{array}$ & $\begin{array}{l}1044.43 \\
\pm 31.42\end{array}$ & $\begin{array}{l}1048.15 \\
\pm 33.38\end{array}$ & $\begin{array}{l}1214.80 \\
\pm 54.18\end{array}$ & $\begin{array}{l}1185.17 \\
\pm 53.02\end{array}$ & $0.11 \mathrm{NS}$ & $-4.08 \mathrm{NS}$ & $-3.12 \mathrm{NS}$ \\
\hline $\begin{array}{c}\text { Control } \\
\text { (No treatment) } \\
(\mathbf{n}=9)\end{array}$ & $\begin{array}{l}1011.11 \\
\pm 30.43\end{array}$ & $\begin{array}{l}1011.11 \\
\pm 30.43\end{array}$ & $\begin{array}{l}1044.00 \\
\pm 31.43\end{array}$ & $\begin{array}{l}1018.50 \\
\pm 27.84\end{array}$ & $0.00 \mathrm{NS}$ & $-1.73 \mathrm{NS}$ & $-1.00 \mathrm{NS}$ \\
\hline
\end{tabular}

NS=Non-significant $* *, p<0.01 *, p<0.05$ Number of goats per group, $n=3 ; 3$ samples from each goat

Albendazole (Table 1) was used as a chemical anthelmintic to control gastrointestinal nematodes in goat. No significant $(\mathrm{p}>1.00)$ reduction in the EPG count on day 4 post-treatment was noticed with dosage of $0.1 \mathrm{ml} / \mathrm{kg}$ body weight compared to pre-treatment. The mean EPG count at day 0, day 4, day 8 and day 20 are $1044.43,1048.15,1214.80$ and 1185.17 respectively. There was also no significant $(p>0.01)$ reduction in EPG count between pre-treatment and post-treatment day 8 and day 20 respectively. Treatment efficacy on day 4 was $0.36 \%$, day 8 was $16.31 \%$ and day 20 was $13.48 \%$. Table 2 shows no significant differences between Albendazole treated group and control group. Significant $(\mathrm{p}<0.01)$ differences between this two groups was only recorded on day 8 of post treatment. Whereas on day 0 , day 4 and day 20 no significant $(p>0.05)$ differences were tabulated between chemical anthelmintic treated group and control group. This outcome is partially in agreement with an experiment conducted by Basripuzi et al. (2012) and Khalid et al. (2013). 
Table 2: EPG count comparative between control group and different group of treatment on the same day

\begin{tabular}{|c|c|c|c|c|c|c|c|}
\hline & \multicolumn{4}{|c|}{ Mean EPG ( Mean \pm SE) } & \multicolumn{3}{|c|}{ t-value } \\
\hline & 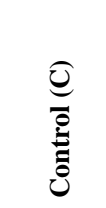 & 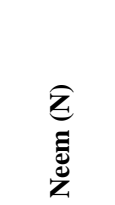 & 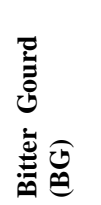 & 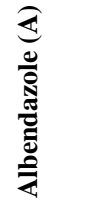 & tC-tN & tC-tBG & tC-tA \\
\hline $\begin{array}{c}\text { Day 0 } \\
\text { (pre-treatment) }\end{array}$ & $\begin{array}{l}1011.11 \\
\pm 30.43 \\
\end{array}$ & $\begin{array}{l}970.36 \\
\pm 166.15\end{array}$ & $\begin{array}{l}855.55 \\
\pm 70.71\end{array}$ & $\begin{array}{l}1044.43 \\
\pm 31.42\end{array}$ & $0.28 \mathrm{NS}$ & $3.04 *$ & $-1.73 N S$ \\
\hline $\begin{array}{c}\text { Day } 4 \\
\text { (post-treatment) }\end{array}$ & $\begin{array}{l}1011.11 \\
\pm 30.43\end{array}$ & $\begin{array}{l}970.36 \\
\pm 166.15\end{array}$ & $\begin{array}{l}855.55 \\
\pm 70.71\end{array}$ & $\begin{array}{l}1044.43 \\
\pm 31.42\end{array}$ & $4.98 * *$ & $7.24 * *$ & $-1.30 \mathrm{NS}$ \\
\hline $\begin{array}{c}\text { Day } 8 \\
\text { (post-treatment) }\end{array}$ & $\begin{array}{l}1011.11 \\
\pm 30.43 \\
\end{array}$ & $\begin{array}{l}970.36 \\
\pm 166.15 \\
\end{array}$ & $\begin{array}{l}855.55 \\
\pm 70.71 \\
\end{array}$ & $\begin{array}{l}1044.43 \\
\pm 31.42 \\
\end{array}$ & $15.50 * *$ & $24.43 * *$ & $-4.08 \mathrm{NS}$ \\
\hline $\begin{array}{c}\text { Day } 20 \\
\text { (post-treatment) }\end{array}$ & $\begin{array}{l}1011.11 \\
\pm 30.43\end{array}$ & $\begin{array}{l}970.36 \\
\pm 166.15\end{array}$ & $\begin{array}{l}855.55 \\
\pm 70.71\end{array}$ & $\begin{array}{l}1044.43 \\
\pm 31.42\end{array}$ & $42.80 * *$ & $8.00 * *$ & $-3.20 \mathrm{NS}$ \\
\hline
\end{tabular}

NS=Non-significant $* *, p<0.01 *, p<0.05$ Number of goats per group, $n=3 ; 3$ samples from each goat

Table 3: Efficacy of methanol extract of A.indica and M.charantia

\begin{tabular}{ccc}
\hline Day & A.indica $(\%)$ & M.charantia (\%) \\
\hline $\mathbf{4}$ & 32.80 & 34.63 \\
$\mathbf{8}$ & 63.40 & 66.23 \\
$\mathbf{2 0}$ & 88.17 & 27.27 \\
\hline
\end{tabular}

It is impossible to calculate from the EPG count the precise size of the parasitic load in the gastrointestinal nematodes infected goats. Too many factors influence both the egg production and the number of eggs found per gram of faeces. A number of male and especially larval worms occur besides egg laying female worms, which can not substantiated by means of EPG count (Rattray, 2003).Immune respond of the gastrointestinal nematodes infected goats is the inhibition of the female nematode's egg production thus causing the number of eggs laid by each nematode to decrease in inverse proportion of the goats' immune system resistant. In some situations the egg production stops completely. Therefore, older goats often present a lower EPG count than younger ones, which may have the same number of nematodes in it. The general state of health, age and level of nutrition are also very important as they influence the effectiveness of the host's immune response. The duration of exposure influences the development and maintenance of an effective immune response, which has a considerable energy cost (Sykes, 1997). The egg production of most nematodes does not seem to occur continuously, but at regular intervals in a cyclic form.

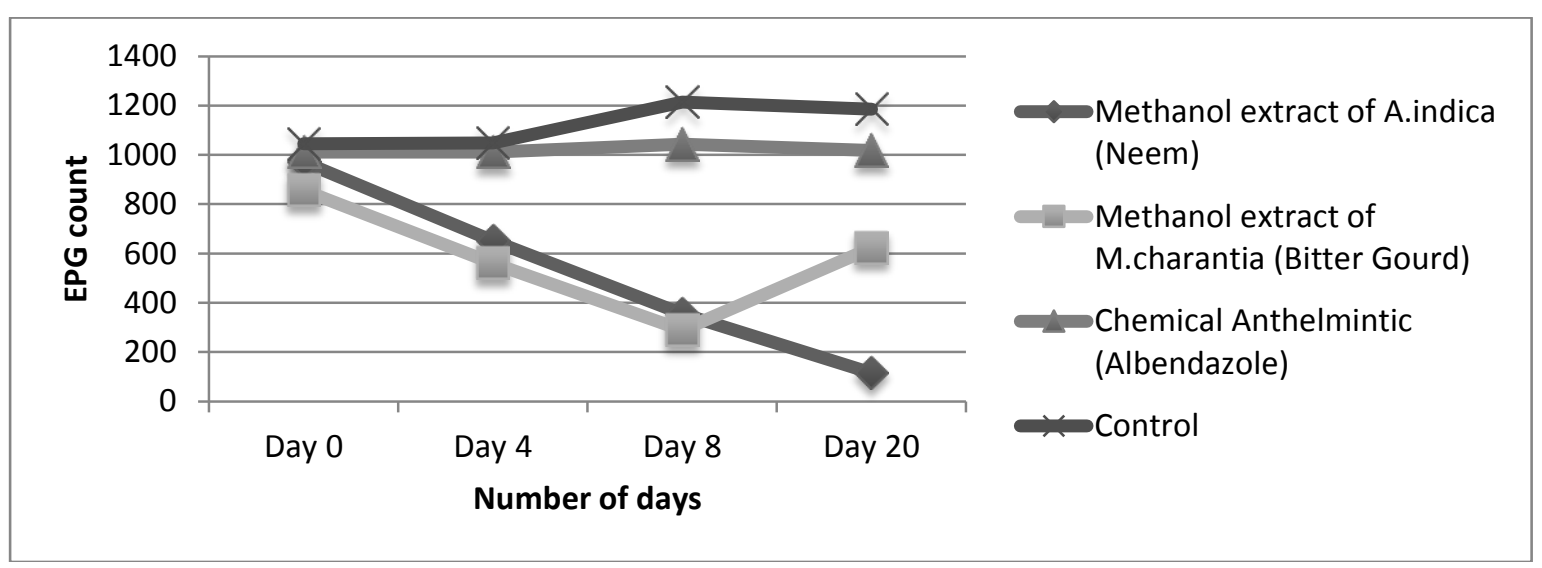

Figure 4.1: Dynamics of EPG count in gastrointestinal nematodes infected goats 
Gastrointestinal nematodes eggs' ability to survive environmental conditions depends on the species and development stage of the parasite when adverse conditions occur. Egg production are higher during hot season, it ensures a rapid rate of development (Chandrawathani et al., 2006).

\section{References}

[1] Akbar, M.A., Ahmed, T.U., Mondal, M.H.(2006). Improving animal productivity and reproductive efficiency: Development and testing medicated urea molasses until nutrient blocks in rural farms of Bangladesh. Improving animal productivity by supplementary feeding of multi nutrient blocks, controlling internal parasites and enhancing utilization of alternate feed resources (pp.14-27). Austria: International Atomic Energy Agency.

[2] Al-Shaibani, I.R.M.S.(2009). Epidemiological study and evaluation of anthelmintics activity of indigenous plants on gastrointestinal nematodes of sheep in Hyderabad district.Sindh Agriculture University, Tandojam, Pakistan.

[3] Athanasiadou, S., Githiori, J. and Kyriazakis, I. (2007). Medicinal plants for helminth parasite control:facts and fictions.Animal,1(9):1392-1400

[4] Chandrawathani, P., Chang, K.W., Nurulaini, R., Waller, P.J., Adnan, M., Zaini, C.M., Jamnah, O., Khadijah, S. and Vincent, N. (2006). Daily feeding of fresh Neem leaves (A.indica) for worm control in sheep.Tropical Biomedicine 23(1):23-30

[5] Costa, C.T., Bevilaqua, C.M., Maciel, M.V., CamurCa-Vasconcelos, A.L., Morais, S.M., Monteiro, M.V., Farias, V.M., da Silva, M.V., Souza, M.M.(2006). Anthelmintic activity of Azadirachtaindica against sheep gastrointestinal nematodes.VetParasitol, 137(34):306-310.

[6] Githigia,S.M., Thamsberg,S.M., Maing,N. and Munyua, W.K.(2005). The epidemiology of gastrointestinal nematodes in goats in the low potential areas of Thinka district, Kenya.Bull.Anim.HealthProd.Afr. 53,5-12

[7] Iqbal, Z., Akhtar, M., Khan, M.N. and Riaz, M. (1993). Prevalence and economic significance of Haemonchosis in sheep and goats slaughtered at Faisalabad abattoir. Pak. J. Agric. Sci., 30:51-53

[8] Irfan, M., (1984).Effects of parasitism in lowering livestock production.Pakistan Vet. J., 4: 25-27.

[9] Lateef, M., Iqbal, Z.,Khan, M.N., Akhtar, M.S., and Jabbar, A. (2003). Anthelmintic activity ofAdhatodavesicaroots.Int. J. Agric. Biol., 5: 86-90.

[10] Rahman, G. \&Seip, H. (2002).Bioactive forage and phototherapy to cure and control endoparasite disease in sheep and goat farming system.A review of current scientific knowledge. Institute of Organic Farming, Agricultural Research Centre (pp.1-6)

[11] Rattray, P.V. (2003). Helminth parasite in the New Zealand meat \& wool pastoral industries: A review of current issues

[12] Sani, R.A., \&Rajamanickam, C. (1990).Gastrointestinal parasitism in small ruminants. In Proc.Workshop on Integrated tree cropping and small ruminant production system. Medan, Indonesia.

[13] Sujon, M.A., Mostofa, M., Jahan.M.S.,Das,A.R., \&Rob, S.(2008). Studies on medicinal plants against gastrointestinal nematodes of goats.Bangl.J.Vet.Med.6(2):179-183

[14] Sykes, A.R. (1997). Effects of nematode parasitism on ruminant animal performance. In: Sustainable control of internal parasites in ruminants. Ed. G.K. Barrell. Animal Industries Workshop, Chapter 7: 81-94.

[15] Worku, M., Franco, R. and Miller, J.H. (2009). Evaluation of the activity of plant extracts in Boer goats.American Journal of Animal and Veterinary Sciences 4(4):72-79 